\title{
PELATIHAN MICROSOFT OFFICE EXCEL SEBGAI UPAYA PENINGKATAN KOMPETENSI SISWA SMK ROSMA KARAWANG DALAM MENGOLAH DATA
}

\author{
Apit Priatna ${ }^{1}$, Dudi Awaludin ${ }^{2}$, Mokhamad Wahidin ${ }^{3}$, Darmansyah ${ }^{4}$ \\ 1,2,3Program Studi Sistem Informasi, STMIK ROSMA \\ ${ }^{4}$ Program Studi Teknik Informatika, STMIK ROSMA \\ Email : ${ }^{1}$ apit.priatna@dosen.rosma.ac.id, ${ }^{2}$ dudi@rosma.ac.id, \\ ${ }^{3}$ m.wahidin@dosen.rosma.ac.id, ${ }^{4}$ darmansah@rosma.ac.id \\ Diterima : 13-06-2021, Di publikasikan : 16-06-2021
}

\begin{abstract}
Abstrak
Informasi yang tepat didapat dengan pengelolahan data. Informasi dibutuhkan oleh organisasi dalam rangka mengambil keputusan bisnis yang tepat. Pembekalan terkait pengolahan data penting bagi siswa Sekolah Menengah Kejuruan(SMK), untuk mendukung kinerjanya ketika di Industri. Pelatihan Microsoft Office Excel 2013 untuk pengolahan data dapat menjadi salah satu strategi mempersiapkan siswa SMK untuk memasuki dunia industri. Pada kegiatan ini, mitra dari pelatihan pelatihan Microsoft Office Excel 2013 untuk pengolahan data adalah siswa SMK ROSMA KARAWANG. Kegiatan ini diawali dengan pre-test yang digunakan untuk mengukur kemampuan siswa. Kemudian dilanjutkan dengan penjadwalan dengan mitra, penyiapan materi yang didasarkan pada hasil pre-test, pelaksanaan dan diakhiri dengan evaluasi capaian pembelajaran. Hasil kegiatan ini, siswa mampu untuk mengolah data dengan berbagai rumus menggunakan Microsoft Office Excel 2013. Kegiatan ini memberikan dampak yang baik untuk peningkatan kompetensi lulusan dan kualitas SMK ROSMA KARAWANG.
\end{abstract}

Kata Kunci : Informasi, Microsoft Office Excel 2013, Sekolah Menengah Kejuruan, Pengolahan data.

\section{Abstract}

The right information is obtained by data management. Information is needed by organizations in order to make the right business decisions. Provision related to data processing is important for Vocational High School (SMK) students, to support their performance when in Industry. Microsoft Office Excel 2013 training for data processing can be one of the strategies to prepare vocational students to enter the industrial world. In this activity, partners from the Microsoft Office Excel 2013 training for data processing were students of SMK ROSMA KARAWANG. This activity begins with a pre-test which is used to measure students' abilities. Then proceed with scheduling with partners, preparing material based on the results of the pre-test, implementation and ending with an evaluation of learning outcomes. The results of this activity, students are able to process data with various formulas using Microsoft Office Excel 2013. This activity has a good impact on improving the competence of graduates and the quality of SMK ROSMA KARAWANG.

Keyword : Data processing, Information, Microsoft Office Excel 2013, Vocational High School. 


\section{PENDAHULUAN}

Dalam proses bisnis suatu organisasi terdapat aliran data. Aliran data digunakan untuk diproses menjadi informasi yang digunakan untuk pengambilan keputusan. Pengolahan atau pemrosesan data menjadi informasi dapat dilakukan menggunakan sistem atau perangkat lunak aplikasi seperti Microsoft Office Exce/ 2013.

Microsoft Office Excel 2013 memiliki kemampuan dalam mendapatkan data, memvisualisasikan data, memfilter data, serta dapat membantu dalam meningkatkan kapabilitas analitik(Support Microsoft, 2021). Menurut web pemerintah yaitu prakerja.go.id menjelaskan bahwa Microsoft Office Exce/2013 merupakan salah satu skill yang harus dimiliki oleh seorang data entry yang handal(prakerja.go.id, 2021). Kemnaker juga telah mendorong para pencari kerja untuk memiliki skill Microsoft Office Excel 2013 untuk mendukung Curiculum Vitae, kegiatan yang dilakukan oleh kemenaker adalah melalui peltaihan mengolah data numerik menggunakan Microsoft Office Exce/ 2013 yang didalam fokus dengan materi pengenalan, fungsi - fungsi, operator , formula ID, Chart grafik, sort and filter, pivot tabel, dan makro(Kemnaker, 2021). Melihat support pemerintah, dan pentingnya skill pengolah data menggunakan Microsoft Office Excel 2013, maka siswa - siswa sekolah Sekolah Menengah Kejuruan(SMK) yang lulusan berfokus untuk siap kerja maupun berwirausaha maka, pelatihan terkait Microsoft Office Excel perlu di lalukan dengan baik.

Pada kegiatan ini, mitra pelatihan Microsoft Office Excel 2013sebagai media pengolah data adalah SMK ROSMA KARAWANG. Tujuan dari kegiatan ini adalah memberikan pembekalan untuk siswa SMK, untuk persiapak di dunia kerja atau industri. Beberapa kegiatan pelatihan terkait peningkatan skill Microsoft Office Excel telah terbukti memberikan dampak yang positif kepada peserta pelatihan seperti pelatihan dilakukan oleh (Yusri, Edriati, \& Yuhendri, 2020), (Ari Waluyo, Hamid Nasrullah, \& Sotya Partiwi Ediwijoyo, 2020), (Salamah, Lindawati, Asriyadi, \& Fadli, 2013), (Wali, M., \& Mukhtar, 2020), (Enjelita, Saragih, Astuti, \& Utama, 2010)

\section{METODE}

Kegiatan ini dilakukan melalui beberapa tahapan diantaranya tahapan pre-test, penjadwalan, penyusunan materi pelatihan, pelaksanaan dan post-test atau evaluasi pelatihan. Pre-test dilakukan untuk mengukur pemahaman awal pengetahuan calon peserta pelatihan. Penjadwalan dilakukan berdasarkan informasi dari mitra kegiatan yaitu SMK ROSMA KARAWANG. Peserta pelatihan ini adalah sebanyak 25 peserta dari berbagai program studi, 
diantaranya program studi Teknik Komputer Jaringan, Aplikasi Perkantoran, dan Teknik Kendaraan Ringan. Materi disusun berdasarn hasil pre-test, materi disusun oleh dosen Program Studi Sistem Informasi STMIK ROSMA. Pelaksanaan dilakukan dengan menyajikan materi, tanya jawab, dan latihan studi kasus. Sedangkan post-test atau evaluasi dilakukan dengan contoh soal yang akan diselesaikan oleh peserta pelatihan.

\section{HASIL DAN PEMBAHASAN}

Kegiatan pelatihan ini dilaksanakan pada tanggal 20 Oktober 2020. Pelaksanaan dilaksanakan dengan sukses dan lancar. Pada saat penyajian materi, pemateri menyajikan konsep yang selanjutnya diikut dengan contoh kasus. Hal ini dilakukan untuk memberikan pemahaman kepada peserta pelatihan tentang implementasi dari konsep yang di ajarkan. Antusias peserta sangat terlihat dengan pertanyaan - pertanyaan yang terlontar tekait soal yang di contoh kan oleh pemateri. Pemateri dengan pelan - pelan mensimulasikan kembali penyelesaian soal agar peserta pelatihan dapat mengikuti sehingga dapat memahami. Dengan pemahaman tersebut, peserta dapat mengaplikasikan pada contoh studi kasus lanjutan yang dimuat oleh pemateri.

Materi yang disajikan pada pelatihan ini diantaranya adalah pemahaman tentang layout pada Microsoft Office Excel 2013, pengenal fungsi - fungsi serta operator seperti IF. Materi dilanjutkan dengan sort and filter, pivot yang dapat mendukung analisis data. Selain itu peserta juga diajarkan cara membuat visualisasi chart dari data yang anda sehingga mempermudah membaca data. Dengan berakhir nya semua materi dan contoh kasus yang disajikan oleh pemateri, maka kegiatan dilanjutkan dengan pelaksanaan post - test atau evaluasi, yang ditujukan untuk mengukur peningkatan pemahaman peserta pelatihan. Post test dilaksanakan dengan memberikan studi kasus kepada peserta pelatihan, yang merupakan rangkuman materi yang telah dipelajari sebelumnya. 
Abdimas : Sistem dan Teknologi Informasi

Vol. 01, No. 01, Juni 2021 : 7-12

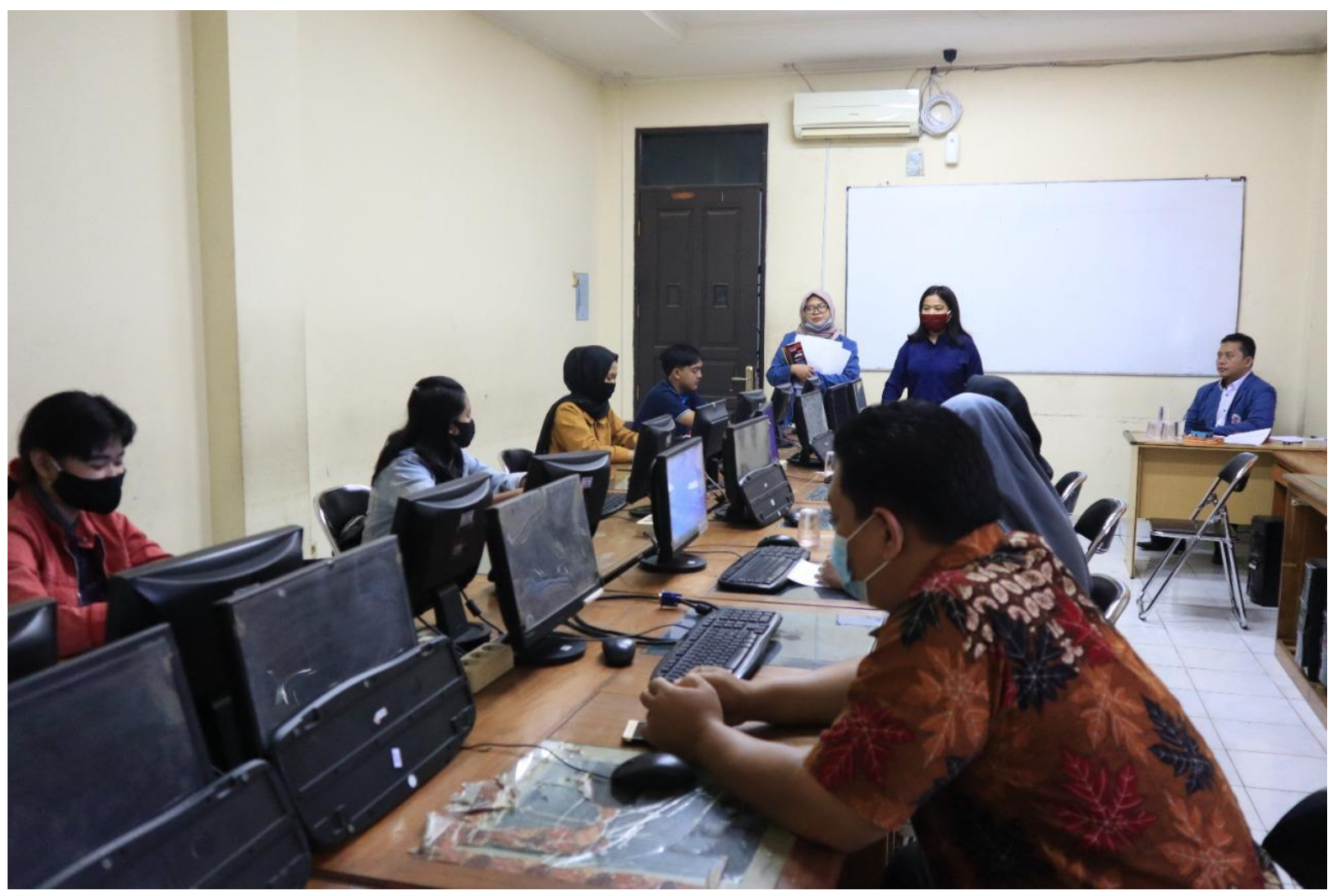

Gambar 1. Kegiatan pelatihan di Laboratorium STMIK ROSMA

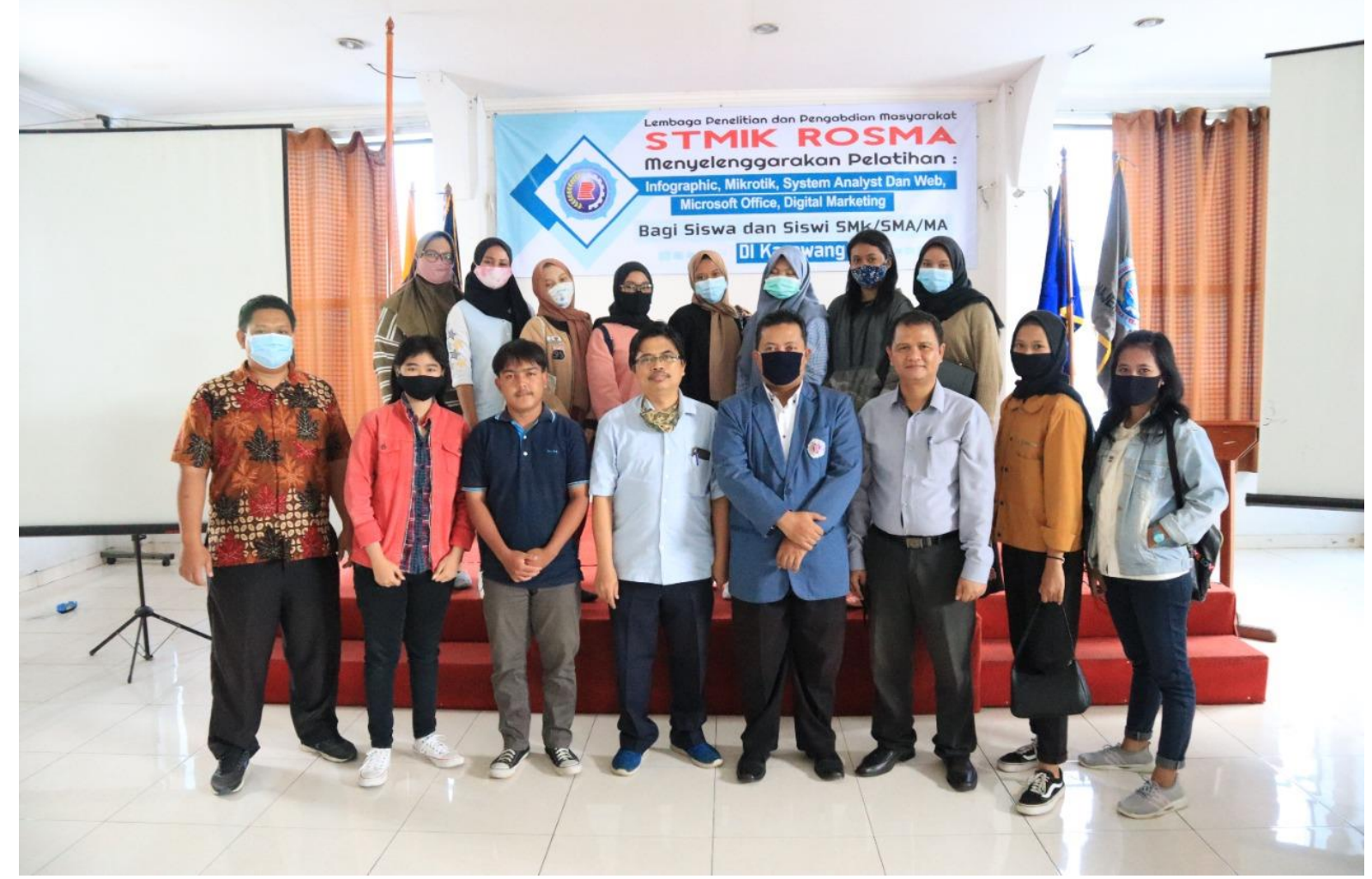

Gambar 2. Foto kegiatan 
Ada beberapa peserta tampak kesulitan mengimplementasikan fungsi atau operator pada studi kasus evaluasi, namun pemateri dengan sigap dapat membimbing peserta sehingga seluruh peserta dapat menyelesaikan seluruh evaluasi. Hasil dari pelatihan ini, menunjukkan bahwa seluruh peserta memahami penggunanan fungsi, operator, sort, filter, chart, dan pivot.

\section{KESIMPULAN DAN SARAN}

Pelatihan Microsoft Ofice Excel 2013 dengan mitra prodi Administrasi Perkantoran SMK ROSMA, berjalan dengan lancar, dari tahapan survei awal, penjadwalan, penyusunan materi, pelaksanaan dan evaluasi. Kesenangan peserta dalam mengikuti pelatihan ini terlihat dari apa yang dihasilkan yaitu mendapatkan pengetahuan baru terkait penggunaan Microsoft Ofice Excel 2013. Melalui kegiatan ini, peserta mendapatkan pengalaman mengembangkan kemampuannya dengan mengambil studi kasus tertentu. Kegiatan ini juga dapat berimplikasi pada SMK ROSMA KARAWANG yaitu meningkatnya mutu lulusan, sehingga dapat mudah terserap di dunia industri.

\section{UCAPAN TERIMA KASIH}

Ucapan terima kasih disampaikan kepada UPT TIK STMIK ROSMA yang telah memberikan ruang kepada kami, serta Kepala Sekolah, Guru dan Siswa SMK ROSMA KARAWANG yang telah berperan dalam kegiatan ini.

\section{REFFERENCE}

Ari Waluyo, Hamid Nasrullah, \& Sotya Partiwi Ediwijoyo. (2020). Pelatihan Penggunaan Apkikasi Microsoft Office (Word, Excel, Power Point) 2010 untuk Peningkatan Kemampuan SDM PEMDES Desa Kebakalan, Karanggayam, Kebumen. JURPIKAT (Jurnal Pengabdian Kepada Masyarakat), 1(1), 21-28. https://doi.org/10.37339/jurpikat.v1i1.273

Enjelita, N., Saragih, N. E., Astuti, E., \& Utama, U. P. (2010). PELATIHAN MICROSOFT EXCEL 2010 PADA SMA. PUBLIDIMAS, 21-26.

Kemnaker. (2021). Mengelola Data Numerik Menggunakan Microsoft Excel (Termasuk Makro Dan Pivot). Retrieved June 13, 2021, from pelatihan.kemnaker.go.id website: https://pelatihan.kemnaker.go.id/programs/a9d5cdf5-216b-4ad5-a51cf3cb12604d44/detail/competencies?previous=\&acceptPreWorkCard=1

prakerja.go.id. (2021). Pertajam 3 Kemampuan Ini untuk Jadi Data Entry Handal. Retrieved June 13, 2021, from prakerja.go.id website: https://www.prakerja.go.id/artikel/pertajam-3-kemampuan-ini-untuk-jadi-data-entryhandal

Salamah, I., Lindawati, Asriyadi, \& Fadli, M. (2013). GURU-GURU SDN 130 PALEMBANG DALAM. SNOPTEKMAS, 11-15.

Support Microsoft. (2021). Kemampuan BI di Excel dan Office 365. Retrieved June 13, 2021, 
Abdimas : Sistem dan Teknologi Informasi

Vol. 01, No. 01, Juni 2021: 7-12

from support.microsoft.com website: https://support.microsoft.com/idid/office/kemampuan-bi-di-excel-dan-office-365-26c0548e-124c-4fd3-aab3$5 f 64568 \mathrm{cb} 743$

Wali, M., \& Mukhtar, M. (2020). Pelatihan Microsoft Excel 2013 Dalam Rangka Membentuk Tenaga Pengajar Yang Profesional. Pengabdian Kepada Masyarakat (PKM), 3(1), 31-34.

Yusri, R., Edriati, S., \& Yuhendri, R. (2020). Pelatihan Microsoft Office Excel Sebagai Upaya Peningkatan Kemampuan Mahasiswa Dalam Mengolah Data. RANGKIANG: Jurnal Pengabdian Pada Masyarakat https://doi.org/10.22202/rangkiang.2020.v2i1.4214

2(1), 32-37. 